\title{
FACULTY PERCEPTIONS OF CURRICULAR DEFICITS IN PREPARING STUDENTS FOR PRACTICE WITH LATINOS
}

\author{
Rich Furman \\ Kimberly Bender \\ Chance W. Lewis \\ Jeffery Shears
}

\begin{abstract}
Qualitative responses to at survey of 314 social work faculty from nearly balf of the graduate schools of social work (MSW programs) in the United States elucidated valuable information about culturally sensitive social work education. This article explores faculty perceptions of the deficits of MSW progrtms in preparing students for culturally sensitive social work practice with Latinos. While nearly $90 \%$ of social work MSW faculty agreed or strongly agreed that it is important to prepare students for work with this population, many perceive that their programs are not currently able to do so adequately. Faculty opinions concerning the nature of the deficits and ways of remedying said deficits are discussed.
\end{abstract}

Key words: social work education, Latinos, cultural sensitivity

\section{INTRODUCTION}

Tn a recent study, nearly $90 \%$ of graduate social work faculty agreed or strongly agreed that it was important to prepare students for culturally sensitive social work pracrice with Latinos (Furman, 2002). The same study reports that only $42 \%$ of MSW faculty agree or strongly agree that their programs are adequately preparing students for culturally sensitive social work practice with Latinos. It is important to understand the reasons why faculty perceived their programs as lacking in this area. This article explores what faculty perceive to be the deficits in their MSW programs in preparing students for this important area of practice. This article reports on data from the above cited study that examined the attitudes of social work education faculty about the breadth of content offered to MSW students to prepare them for culturally sensitive practice with Latinos. The overreaching issue wirh which this study was concerned is the extent to which sacial workers are prepared for culturally sensitive practice with Latinos in a manner and scope responsive to the service needs of this population. Some of the most fascinating data from this study was obtained through the open ending questions where faculty discussed their impressions of their curriculum vis a vis culturally sensitive practice. Implications are drawn from these findings and tentative

Rich Furman, PhD is Associate Professor \& BSW Coordinator, Deparment of Social Work, College of Healch and Human Services, University of North Carolina Charlorte. Kimberly Bender, MSW is PhD Student, University of Texas at Austin. Chance W. Lewis, PhD is Assiscant Professor, School of Education, Colorado State University. Jeffery Shears, PhD is Assistant Professor, School of Social Work, and Center for American Studies in Erlnicity, Colorado State University.

Copyright @2006 Aduatues in Social Work Vol. 7 No.1 (Spring 2006) 33-43. 
recommendations are made.

\section{RATIONALE: THE IMPORTANCE OF PREPARING STUDENTS FOR PRACTICE WITH LATINOS}

Culturally sensitive practice holds a significant place within social work and social work education. However, in spite of the importance of culturally sensitive practice and the training of culturally sensitive practitioners, it remains one of the most neglected areas of research and pedagogy (Garcia \& Van Soest, 1997). It has been suggested that the issue is no longer "if" culturally sensitive social work practice should be taught, but how research can be promoted to ascertain the most effective strategies for engaging in and teaching cross cultural practice (Asamoah, 1996).

The Council on Social Work Education, in its accreditation guidelines for Masters of Social Work Programs, dedicates one of its eight evaluation standards to the problem of discrimination (CSWE, 1996). Moreover, the CSWE mandates that sensitivity to different cultures be infused throughout the curriculum.

The Code of Ethics of the National Association of Social Workers clearly places the needs of clients from different cultures as a central ethical mandate of the profession (NASW, 1996). The Code mandates that social workers promote respect for cultural diversity. This notion of respect is expanded into the responsibility of action through Secrion VI, Number 1, of the Code of Ethics (1996), which states:

Social workers should act to prevent and eliminate discrimination against any person on the basis of race, culture, sex, sexual orientation, age, religion, national origin, marital status, political belief, mental or physical handicap, or any other preference or personal characteristic, condition, or status (p.7).

This study is relevant to social work education and practice in several ways. As Latinos become a larger proportion of the U.S. population, there is a greater need for social work education to provide culturally sensitive training to social work students (Iglehart \& Becerra, 1995). Since the literature suggests that social work education programs currently may not adequately train students for multicultural practice, an empirical analysis of the adequacy of typical social work education is indicated (Greene, 1994).

Several interlocking suppositions demonstrate the study's relevance and provide a rationale for this research: 1) shifting demographics that will lead to an increasing representation of Latinos in the United States; 2) the social service needs of Latinos; 3) the need and mandate for culturally sensitive social work practice; 4) the current lack of clarity regarding culturally sensitive social work; and 5) the globalization of social and economic institutions. Each of these topics will be discussed briefly, and will be explored in greater depth later in this document.

Latinos are one of the fastest growing ethnic groups in the Unired States. In fact, it is estimated that Latinos will account for $24.5 \%$ of the U.S. population by the year 2050 , increasing from the current $11.4 \%$ (U.S. Bureau of Census, 1998). Several geopolitical factors have led to this continuing growth. Economic crises within Mex- 
ico have dramatically increased the Mexican population in the American Southwest and West. Unstable and oppressive political systems within the countries of Central America have led to an influx of Guatemalans, Honduranians, El Salvadorans and Nicaraguans. Latinos also have higher birth rates than whites or African Americans (Delgado, 1999; Iglehart \&c Becerra, 1995).

Second, Latinos are also one of the poorest and most needy minority groups (Goldenberg \& Goldenberg, 2002), but traditionally underutilize many social and mental health services (Padilla, Ruiz, \& Alverez, 1989). Many refugees from Central Anerica not only face the dilemmas of social and economic dislocation, but also must confront issues of trauma related to having witnessed or experienced intimidation, murder, and even genocide. Also, discrimination and prejudice characterize the struggles of Latinos in the United Stares.

As a result of low socioeconomic status, linguistic isolation, urbanization, and discrimination, the problems of substance abuse, HIV/AIDS, and mental illness greatly impact Latino communities (Carrasquillo, 1991; Colon, 1996). Many commentarors have drawn connections between social forces and mental health and health needs (Fanon, 1963; Gil, 1973; Jenkins, Kleinman, \& Good, 1991). Zuniga (1987) observes that the social/political realities of poverty and discrimination result in negative selfconceptions among Chicanos. In spite of these multiple stressors encounrered by Latinos, as a group they typically underutilize mental health and social services due to the lack of culturally sensitive care by helping professionals (McGowan, 1988; Padilla, Ruiz, \& Alverez, 1989).

The Latino population is greatly underrepresented among students in social work education programs, accounting for approximately 3\% of MSW students (CSWE, 1998a). While increasing ethnic diversity within the profession is a goal (CSWE, 1998b), nevertheless it is imperative that non-Latino social work students are trained to provide culturally comperent services.

Social work is a rapidly internationalizing profession. Along with other social and economic institutions, social work and social welfare institutions are becoming increasingly globalized (Lusk \& Stoesz, 1994; Sanders \& Pedersen, 1984). The implementation of the North American Free Trade Act signifies a move toward greater socioeconomic integration in the Americas. This integration, along with the internationalization of many social welfare institutions, provides further support for crosscultural and multicultural training (Estes, 1992).

The need for empirical research on culturally sensitive social work practice is widely recognized. As early as the late 1960's the profession, as represented by CSWE and NASW, recognized the need for infusing culturally relevant issues into professional training (Longres, 1991). Nevertheless, few empirical studies of ethnically sensitive education or practice have been undertaken (Beidler \& Chalmers, 1978; Garcia \& Van Soest, 1997).

Much debate exists as to what constitures culturally sensitive social work practice, the degree to which relevant content is currently infused into curriculum, and the effectiveness of such methods (Hopps, 1988). Colon (1996) emphasizes the need for a 
"generalized sensitivity" to cultural factors in working with Latinos. Such a sensitivity is developed by understanding the diversity within the Latino community, the nature of the Latino family, and the importance of folkways and community supports for health and mental health treatment.

Others emphasize the importance of understanding the role of powet, oppression, and racism as the keys to culturally sensitive practice (Pinderhughes, 1979). For example, Williams (1988) views power and oppression as the "organizing mechanism" through which other issues pertaining to multicultural social work should be taught. Devore and Schlesinger (1991) take a more comprehensive approach that seeks to impart a combination of knowledge, insight, and skill.

As the Latino population continues to increase, many more social workers will be called upon to work with Latino clients. These demographic trends necessitate an understanding of the adequacy of culturally sensirive social work educational material for those entering social work practice. In addition, even if Latinos were not increasing as an overall proportion of the population, cultural and social factors unique to Latinos require social workers to be trained in appropriate culturally sensitive practice. By ascertaining the nature and breadth of culturally sensirive social work content and the attitudes of faculty regarding culturally sensitive social work educarion, the profession will have a base upon which to assess the adequacy of curriculum and the extent to which CSWE mandates are being met.

\section{METHODOLOGY}

Data gathered in this report were collected by an instrument created to ascertain faculty perceptions about culturally sensitive social work education. The data presented in this study come from the qualitative section of this research instrument. The study population consisted of full-time faculty in graduate schools of social work. A probability sampling method was used to obtain 314 participants out of a random sample of 1,050 faculty member with 2,000 being the total U.S. population of MSW faculty. At the rime of the study, there were nearly 2,000 full-time faculty in accredited MSW programs. Statistical analysis demonstrated that a representative sample of this population would be 325 participants.

While the unit of analysis in this sampling method is not schools of social work per se, but faculty, using individual schools of social work as the sampling frame has been successfully utilized previously (Birnbaum \& Auerbach, 1994). All faculty within schools of social work were randomly selected and were asked to participate in the study, i.e., half of all MSW programs were selected randomly, and all faculty from each of these schools were surveyed. Lists of faculty who teach full-time in the selected schools were available through the World Wide Web pages of the schools of social work. If a school of social work did nor have this information on the World Wide Web, it would have been obtained from a copy of the latest catalogue. It is interesting to note that this was not necessary. All of the schools that were randomly selected did have faculty informarion that was sufficient for this study. "This should be of methodological importance to subsequent researchers who are considering utilizing this merhodology. The convenience and accuracy of the using the World Wide Web as a sampling frame 
seems to warrant its use in various research settings.

Data was analyzed using a five round system of thematic analysis that utilizes negative case analysis and checks by multiple researchers to insure rigor. Once themes and parterns were established and labeled, researchers began searching more data for the presence or variances of these themes. In consistently reevaluating, re-defining, and openly exploring the website material, researchers built theory by making comparisons (Neuman, 1997).

\section{FINDINGS}

\section{Frequency of responses}

The primary survey question that addresses the focus of this paper asks: How can your MSW program improve in preparing students for culturally sensitive social work practice with Latinos. Data will also be reported quantitatively as frequency counts. Narrarive data will be presented in the next section.

Two hundred eleven (67\%) of the faculty who responded to the questionnaire chose to answer this open-ended question. Answers ranged from one or two word responses to longer answers of four or five sentences.

The most frequent responses were from faculty who wrote that their programs could most improve by hiring more Latino faculty. Fifty-eight faculty indicated this answer in their response. Several of these faculty also mentioned the importance of retention of Latino faculty. The next most frequent response were faculty who noted that their MSW programs could most improve in preparing srudenrs for culturally sensitive social work practice with Latinos by adding more content. Forty-one faculty responded with this position. Seven faculty further specified that more audio and visual materials perraining to Larinos were needed. Three faculty answered that more books and articles would improve their programs.

Forty faculty wrote responses pertaining to the recruitment of more Latino students. This was a populat response for faculty who also saw the need for more Latino faculty. One faculty wrote that her program could "be more accepring of differences. Put more time and energy into recruiting Latino faculty."

Increasing the number of field placements was written by 26 faculty. This was followed by 25 faculty who saw the need for Latinos as a group to be recognized as being important in their programs. Following in frequency were 15 faculty each who wrote that material pertaining to Latinos should be infused more successfully in the curriculum and an equal number who stated that faculty need training pertaining to Latino issues. Fourteen faculry stated that an additional course would be the best way to improve their program.

Nine faculty wrote that their program could improve if it had more involvement with the Latino community. Eight faculry wrote that increasing research and scholarship pertaining to Latino concerns would be a significant way to improve their program. Eight faculty also believed that their MSW programs overly focus on the needs 
of African Americans at the exclusion of focusing on Latino and other minority populations.

Less frequent responses included the use of case studies abour Latinos (four), focusing on skills related to practice with Latinos (four), changes in CSWE policy (three), improved integration of material (three), and increasing the globalization of social work curriculum, with a particular focus on Latin America (two).

\section{Narratives of responses and contextualizing discussion}

In general, the findings seem to suggest that faculty perceive culturally sensitive social work with Latinos and Latino material as neglected areas of the social work curriculum. It is worthwhile to note that the degree to which faculty perceive this deficit contrasts strongly to the degree to which faculty believe that teaching this materials is important. Nearly $90 \%$ of faculty agreed or strongly agreed that it was important for MSW programs to prepare students for culturally sensitive practice with Latinos. This suggests that other factors besides faculty perceptions pertaining to the value of teaching this material are at work.

One possible reason for this discrepancy lies in MSW programs actual ability, or inability, to prepare students for practice with Latinos. Data suggest that while faculty in MSW programs recognize the importance of preparing students to work with Latinos, several factors pertaining to MSW programs themselves, as well as factors outside of the university, contribute to this phenomenon.

First, many faculty perceive the lack of Latino faculty as a significant problem for their programs. This is supported by CSWE statistics that show that Latino faculty are indeed underrepresented on social work faculty. Fifty-eight faculty remarked that their programs would do well to hire more Latino faculty. Several faculty commented on the need to hire more Latino faculty to lend more expertise: "Their program should add Hispanic faculty with a strong desire to teach this content and have an insider's knowledge base. All other faculty need to continually increase their knowledge base as well."

Other faculty brought up similar concerns. While it could be argued that it would be most important to have Latino faculty in areas of high Latino concentrations, it may be just as essential for schools of social work in areas with few, but growing, Latino populations to have Latino colleagues on staff. In areas with higher population concentrations of Latinos, non-Latino faculty and student have greater opportunity for cross-cultural experiences with Latinos than in areas with fewer Latinos.

Increasing Latino faculty throughout MSW programs would be important for other reasons. First, it will be increasingly difficult to attract and retain Latino students withour faculty mentors who can help ease their transition to graduate school. Minority students may feel isolated when faculty of their same race or ethnicity are not represented. This is especially true given the low numbers of Latino students with whom to connect. Second, Latino faculty are needed to provide a perspective on various aspects of Latino culture. Latino faculty also would be more in tune with the sometimes 
subtle, other times nor so subtle, differences berween different Latino culrures. Third, Latino faculty could provide more direction and leadership in helping schools of social work to connect with Latino clients and Latino-serving agencies. Non-Latino faculty may not be aware of the culcural variables that often make connecting to this community challenging. Further, non-Latino faculty will not have the same investment in establishing this contact with the Latino community. It is the belief of this author that increasing the number of Latino faculty in the United States would be one of the most significant means of improving services to Latinos in the long run.

Faculty also perceive the lack of Latino students as a major impediment to preparing students for culturally sensitive practice. Increasing the number of Latino scudents may be as important a means of improving culturally sensitive social work with Latinos as is increasing the number of faculty. Without Latino students to present their perspectives, few quality class discussions could occur for students and faculty with limited knowledge of this population. Even for students and faculty who have in-depth familiarity with or who have worked with Latinos, Latino students provide an insider's view that is otherwise not available. Many students learn best from less didactic, more interactive types of learning. Having diverse classrooms helps faculty to facilitate discussions among students with diverse values, beliefs, and world views.

Having more Latino students in social work programs would also help combat the potential of stereotyping that can accompany didactic learning pertaining to other cultures. Students will be able to understand that there exist as many intra-group differences as there are inter-group differences. Through interacting with more Latinos, students will begin to understand the role that individual, universal, and cultural factors have on the development of identify.

While faculty perceive preparing students to work with Latinos as important, faculty recognize that competing curricular demands and the need to teach content regarding other minority populations are also extremely important. Often, other ethnic minority groups received the majority of attention in the curriculum. One social work faculty discussed this dynamic: "Most work regarding culturally sensitive social work, diversity and justice focus on working with African Amcricans. The deep south has far to go in black-white relations. Although the Latino population is expanding, this issue takes a back seat."

Another remarked that: "We do not have enough specific content on Latinos and other groups. Students state that we over emphasize cultural sensitivity with African Americans and neglect other cultures."

Other faculty recognized and were concerned with MSW programs and social work in general ignore the changing demographics of the United States and their communities: "(We need to) Recognize that Latinos are a fast growing group in our state. This is a recent development but we cannot ignore it. Historically, we have cmphasized African Americans as the only minority group and the only group to have experienced historical and current oppression."

Another related curricular deficit is reflected by the 14 faculty who remarked that faculty training and development pertaining to Latinos are needed. Faculty noted that 
in-service training and faculty development were needed to help non-Latino faculty understand the complex issues of Latinos. One faculty observed that without training and guidance from Latino colleagues, social work faculty ran the risk of stereotyping Latinos.

Several factors external to MSW programs were also perceived to block schools of social work from preparing students for culturally sensitive social work with Latinos. The paucity of Latino MSW students was conceptualized as a problem that could be more adequately addressed by MSW programs, but with impinging social factors. Latino students currently account for only $3 \%$ of MSW students, while accounting for more than four times that percentage in the general population.

Thirty-five faculty remarked that the recruitment of Latino students was a key issue toward improving the ability of their program to prepare students for practice with Latinos. Many saw the Latino student, similar to the Latino faculty, as being needed to provide an insider's perspective about the Latino experience. The main outside factor seen as inhibiting MSW programs ability to recruit Latino students was the lack of students who applied to their programs. Several faculty commented on the low numbers of Latinos graduating with bachelors degrees. Many Latinos that do graduate with undergraduate degrees of ten have multiple opportunities for graduate training in arcas that are more lucrative than social work.

Second, the need for more students who speak Spanish is seen as a difficult dilemma presented to MSW programs already struggling to meet CSWE requirements. Twenty-one faculty noted the need for more students who speak Spanish. While the numbers of MSW students that do speak Spanish are unknown, it is suspected that they are a relatively rare minority. In the experience of this author, many of those who do speak Spanish do so only on a level far too elementary to be able to perform social work functions.

With so few faculty who are Latino or who speak Spanish, there is a significant gap in social work faculty"s ability to serve this population. Even though agencies typically pay more for workers who speak Spanish, such workers are difficult to find. Not being able to find enough social workers to meet the needs of Spanish-only speaking clients is one of the most common complaints of social welfare agencies in Northern Colorado, where this author is a faculty member in a MSW program.

Third, the lack of placements in agencies serving Latinos was seen as a significant problem. For students who do not speak Spanish, but have an inclination to work with Latinos, the lack of field placements may lead them to work with other populations. If students are not provided with opportunities to work with Latinos while in graduate school, especially those who do not have a command of the Spanish language, it is unlikely that they would feel comfortable, nor be competent, to serve this community. One faculty remarked that their program would be improved: "By having field agencies and more field instructors that are culturally comperent (with Latinos). The field placement is where students have the opportunity to apply the things they have learned."

Another of the main areas that faculty perceived as lacking pertained to the actual 
content within the curriculum. Several types of responses demonstrated this sentiment. Forty-one faculty directly stated that content was lacking in their MSW programs.

Additionally fifteen faculty noted that the material was not infused well enough into the curriculum. This reinforces the quantitative data, which suggest that many faculty perceive this material as being inadequately infused throughout the curriculum. As the infusion model of teaching culturally sensitive social work was by far the most common method of teaching this material in MSW programs, the degree to which it is infused is essential. One faculty eloquently expressed her concern about infusion: "We seem to pay lip service to this (infusion). We say that material of each ethnic group should be taught in each course, but I would say only one or two courses in the curriculum ever even mention Latinos."

\section{CONCLUSION}

As social work expands and changes in the new millennium, it will need to address how we are preparing students for culturally sensitive social work practice with Latinos and other populations. Social work educational programs must contend with the interests of many constituencies that vie for a place in the curriculum. With greater and greater demands on curriculum committees to include material about outcomebased practice, specific information about various disabilities, as well as demands from other important cultural, ethnic and minority groups, preparing students for practice with Larinos will demand focus and dedication. This must also be balanced with the importance of preparing students for work with other culturally diverse populations. Social work educators must reexamine their curriculums to make certain students are prepared for culturally competent practice with all many populations.

As segments of the Latino community remain among the poorest populations in the United States, social work education must actively recruit Latino students to the profession through finding scholarships and financial aid for Latino students. Further, schools of social work must think of creative ways of marketing itself to this population. Other professions, such as education, have had a fairly successful history of getting African American students to pursue advanced degrees by offering incentives such as free masters degrees if one teaches in an at risk-area. School of social work would do well to develop partnerships with social service agencies to help create such solutions. As we increase the number of Latino MSWs, we can begin to recruit them into PhD programs and incrense the numbers of Latino faculty. Increasing the numbers of Latino faculty should help increase the number of Latino students.

Social work programs can also provide extensive professional development activities for faculty in regard to culturally sensitive practice with Latinos. Faculty must be trained in teaching culturally sensitive social work for practice with Latinos. As it may take many years before the number of Latino faculty increase, faculty from other ethnic groups must be prepared to help student work with this often needy and misunderstood population. School of social work may also extend such training to community social workcrs, thus creating partnerships and exchanges of resources and ideas. 
Social work programs must make decisions about infusing material related to Latinos throughout their curriculum or into specific courses. If schools adopt the infusion model, they must find structural ways of assuring that material truly is infused in each course. If not, the end result could be infusion only for purposes of accreditation. Also, curriculum should be developed that both challenges and validates the worldviews of students. Teaching culturally sensitive practice must not invalidate the valuable experiences of scudents from any cultural group. No one group should privileged over another. Thus, integrative models that incorporate the commonalities of all people, as well as their differences, must be developed.

\section{References}

Asamoah, $Y$. (1996). Innovations in delivering culturnlly sensitive social wark services. New York: Haworth Press.

Beidler, R. J., \& Chalmers, M. A. (1978). A preliminaty report to the doctoral planning committee concerning minority thrust in the doctoral program, 1974-1977. Research Report \#78-06. Philadelphia, PA: University of Pennsylvania, Center for the Study of Social Work Practice.

Birnbaum, M. L., \& Auerbach, C. (1994). Group work in graduate social work education: The price of neglect. Journal of Social Work Education, 30(3), 325-335.

Carrasquillo, A. (1991). Hispanic children and youth in the United States: A resources guide. New York: Garland.

Council on Social Work Education. (1998a). Statistics on social work educttion: 1998. Alexandria, VA: Author.

Council on Social Work Education. (1998b). Revisions to evaluation standards. Alexandria, VA: Author.

Colon, E. (1996). Program design and planning strategies in the delivery of culturally competent health and mental health services to Latino communities. In. Y. Asamoah (Ed)., Innovittions in delivering culturally sensitive social work services (pp.164-182). New York: Haworth Press, Inc.

Delgado, R. (1999). Generalist child welfare and Hispanic families. In. N. A. Cohen (Ed). Child welfare: A multicultural focus (pp.165-190). Boston: Allyn \& Bacon.

Devore, W., \& Schlesinger, E. G. (1991). Ethnic-sensitive social work practice. New York: Macmillian.

Estes, J. R. (1992). Internationalizing social work education. Philadelphia: University of Pennsylvania.

Fanon, F. (1963). The wretched of the earth. New York: Grove Weidenfeld.

Furman, R. (2002). Culturally sensitiue social work education with Latinos Doctoral dissertation. New York: Yeshiva University.

Garcia, B., \& Van Soest, D. (1997). Changing perceptions of diversity and oppression: MSW students discuss che effects of a required course. Joumal of Social Work Educttion, 33(1),119129.

Gil, D. G. (1973). Unrateling social policy. Rochester, VT: Schenkman Books.

Goldenberg, H., \& Goldenberg, I. (2002). Counseling today's families (4th ed.). Pacific Grove, CA: Books/Cole.

Greene, R. R. (1994). Human behavior theory: A diversity framework. New York:Aldine de 


\section{Gruyter.}

Hopps, J. G. (1988). Deja-vu or new vicw. Social Work, 33(4), 291-292.

Iglehart, A. P., \& Becerra, R. M. (1995). Social senvices and the athic community. New York: Allyn \& Bacon.

Jenkins, J. H., Kleirman, A., \& Good, B. J. (1991). Cross-cultural studies of depression. In J. Becker \& A. Kleinman (Eds.). Pychosocial aspects of depression (pp. 67-99). Hillsdale, NJ: Lawrence Erlbaum.

Lee, M. Y. \& Greene, G. J. (1999). A social constructivist frantework for integrating cross cultural issues in teaching clinical social work. Jourmal of Social Work Edtcation, 35(1), 21-37.

Longres, J. F. (1991). Toward a starus model of ethnic sensitive practice. Journal of Multicultural Social Work, 1(1), 41-53.

Lusk, M. W., \& Stoesz, D. (1994). International social work in a global economy. Journal of Multicultural Social Work, 3(2), 101-113.

McGowan, B. G. (1988). Helping Puerto Rican families at risk: Responsive use of time, space, and relationships. In C. Jacobs \& D. D. Bowles (Eds.). Ethnicity and race: Critical concepts in social work (pp. 48-70). Silver Spring, MD: Narional Association of Social Workers.

National Association of Social Workers. (1996). NASW code of etbics. Washingron, DC: Author.

Neuman, W. (1997). Social resettrch methods. Boston, MA: Allyn and Bacon.

Padilla, A. M., Ruiz, R. A. \& Alvarez, R. (1989). Community mental health services for the Spanish speaking/surname populations. In. D. R. Atkinson, G. Morten, \& D. W. Sue (Eds.). Counseling American minorities: A cross-cultural perspective. (167-198) Dubuque, IA: Wm. C. Brown.

Pinderhughes, E. B. (1979). Teaching empathy in cross-cultural social work. Social Work July, $312-316$.

Sanders, D., \& Pedersen, P. (1984). Education for international social welfare. Honolulu: University of Hawaii School of Social Work.

Zuniga, M. E. (1987). Mexican American clinical training: A pilot project. Journal of Social Work Education, 23(1), 11-20.

\section{Author's Note}

Address correspondence to Rich Furman, PhD, Associate Professor \& BSW Coordinator, Department of Social Work, College of Health and Human Services, University of North Carolina Charlotte, 9201 University City Blvd. Charlotre, NC 28223. email: rcfurman@email.uncc.edu 